\title{
Rate of individuals with clearly increased radiosensitivity rise with age both in healthy individuals and in cancer patients
}

\author{
Barbara Schuster ${ }^{1}$, Anna Ellmann ${ }^{1}$, Theresa Mayo ${ }^{1}$, Judith Auer ${ }^{1}$, Matthias Haas ${ }^{2}$, Markus Hecht ${ }^{1}$,
} Rainer Fietkau ${ }^{1}$ and Luitpold V. Distel ${ }^{1 *}$ (i)

\begin{abstract}
Background: The question of an age dependence of individual radiosensitivity has only marginally been studied so far. Therefore, we analyzed blood samples of healthy individuals and cancer patients of different ages to determine individual radiosensitivity.

Methods: Ex vivo irradiated blood samples of 595 individuals were tested. Chromosomes 1, 2 and 4 were stained by 3-color fluorescence in situ hybridization and aberrations were analyzed. Radiosensitivity was determined by the mean breaks per metaphase (B/M).

Results: Healthy individuals (mean age 50.7 years) had an average B/M value of $0.42 \pm 0.104$ and an increase of $0.0014 \mathrm{~B} / \mathrm{M}$ per year. The patients (mean age 60.4 years) had an average B/M value of $0.44 \pm 0.150$ and radiosensitivity did not change with age. In previous studies we found that from a value of $0.6 \mathrm{~B} / \mathrm{M}$ on an individual is considered to be distinctly radiosensitive. The portion of radiosensitive individuals $(B / M>0.6)$ increased in both cohorts with age.
\end{abstract}

Conclusion: Individual radiosensitivity rises continuously with age, yet with strong interindividual variation. No age related increase of radiosensitivity can be demonstrated in patients due to the strong interindividual variation. However among old cancer patients there is a higher probability to have patients with clearly increased radiosensitivity than at younger age.

Keywords: Radiosensitivity, 3-colour fluorescence in situ hybridization, Chromosomal aberration, Breaks per metaphase, Individual radiosensitivity

\section{Background}

It is widely believed that human radiosensitivity increases with age due to an increase of oxidative stress, telomere attrition, a decline in DNA damage response efficiency and inflammatory response [1, 2]. Especially DNA double stand break repair seems to be affected. Studies with $\gamma \mathrm{H} 2 \mathrm{Ax}$ staining found that $\gamma \mathrm{H} 2 \mathrm{Ax}$ foci accumulated with older age reflecting unrepaired DNA damage [3-6]. However it is still unclear whether the remaining DNA double strand breaks result in an

\footnotetext{
* Correspondence: Luitpold.Distel@uk-erlangen.de

${ }^{1}$ Department of Radiation Oncology, University Hospital Erlangen

Friedrich-Alexander-Universität Erlangen-Nürnberg, Universitätsstr. 27, 91054 Erlangen, Germany

Full list of author information is available at the end of the article
}

increased radiosensitivity along with a higher risk of radiotherapy related side effects. Clinical studies show contradictory results and are time-consuming $[2,7-10]$. A possibility to estimate individual radiosensitivity is to study the occurrence of radiation induced chromosomal aberrations after ex vivo irradiation.

Since the end of the last century chromosomal aberrations were used to predict patient's radiosensitivity with the aim to individualize dose or fractionation in clinical radiotherapy [11-14]. Several studies were able to predict individual radiosensitivity using different techniques [15-18]. Different time points were used to irradiate lymphocytes. In the G0 assay lymphocytes were irradiated ex vivo in the G0 phase and were stimulated afterwards [14] while in the G2 assay lymphocytes were

(c) The Author(s). 2018 Open Access This article is distributed under the terms of the Creative Commons Attribution 4.0 International License (http://creativecommons.org/licenses/by/4.0/), which permits unrestricted use, distribution, and reproduction in any medium, provided you give appropriate credit to the original author(s) and the source, provide a link to the Creative Commons license, and indicate if changes were made. The Creative Commons Public Domain Dedication waiver (http://creativecommons.org/publicdomain/zero/1.0/) applies to the data made available in this article, unless otherwise stated. 
stimulated first and irradiated afterwards [18]. Either metaphases were analyzed after staining all chromosomes by conventional stains [18] or some of the chromosomes were painted by fluorescence in situ hybridization [19]. Mostly two different scoring protocols were used to classify aberrations. The PAINT system by Tucker et al. [20] and the S\&S system by Savage and Simpson [21]. In spite of all these differences in the majority of studies chromosomal aberrations were able to predict individual radiosensitivity [15-18, 22-25]. The reason why chromosomal aberration testing is not the standard assay of predicting radiosensitivity is probably the time consuming assay and the need of an expert to score the metaphases.

Lymphocytes of the peripheral blood are commonly used because they are easy to obtain. Furthermore, they are in the G0-phase and therefore no cell cycle dependent difference in radiosensitivity occurs. After ex vivo irradiation, lymphocytes have to pass through damage processing and control functions. These are at least repair of the different ionizing radiation induced DNA damages, signaling transduction, induction of cell death and cell cycle arrest. If these functions are impaired, this can lead to an increased radiosensitivity. After carrying out all these essential checks, lymphocytes can enter metaphase. Therefore chromosomal aberration analysis tests for the most important cellular functions and therefore this late endpoint has the potential to predict radiosensitivity based on different reasons.

Our approach was to study the radiosensitivity in dependence of age in a cohort of healthy individuals and a cancer patient cohort. In the healthy individual cohort we expected to have a lower proportion of outliers and get a clearer correlation of radiosensitivity and age. The cancer patient cohort is the relevant cohort for clinical radiotherapy. With both cohorts together we expected to clarify a possible age dependence of radiosensitivity.

\section{Methods \\ Patients}

Whole blood samples (heparinized blood) of 393 patients with various cancers and of 202 healthy individuals were drawn (Table 1). Healthy individuals were defined to have no history of a malignant disease and to have a Karnofsky performance status of at least 90. Cancer patients were defined to have or have had at least one malignant disease. For the study malignant neoplasms of the lymphatic and hematopoietic tissue (ICD-10, 200-208) and nonmelanoma skin cancers (ICD-10, C44) were excluded. Rectal cancer (2009-2015), breast cancer (2011-2013) and head and neck cancer (2013-2014) patients were consecutively sampled in the university hospital of ErlangenNürnberg. All blood samples were taken prior to radiotherapy with the exception of twelve patients. For those
Table 1 Characteristics of patients and healthy individuals

\begin{tabular}{lll}
\hline & Patients & Healthy individuals \\
\hline$n$ & 393 & 202 \\
Gender (\%) & & \\
$\quad$ Male & $208(52.9)$ & $90(44.6)$ \\
$\quad$ Female & $185(47.1)$ & $112(55.4)$ \\
Age (years) & & \\
Mean age & 60.4 & 50.7 \\
Range & $17-91$ & $9-81$ \\
Cancer patients (\%) & \\
Rectal carcinoma & $203(51.6)$ & \\
Breast carcinoma & $101(25.7)$ & \\
Lung cancer & $34(8.7)$ \\
Head and neck tumours & $21(5.3)$ \\
Melanoma & $8(2)$ \\
Prostate Cancer & $3(0.8)$ \\
Other & $23(5.9)$
\end{tabular}

post radiotherapy patients blood was taken at least 4 month after the end of radiotherapy. Parts of the breast cancer data (67 patients) and healthy individuals data (62) were previously published [26].

\section{Chromosome preparation}

The patients' blood was drawn prior to radiation therapy. Blood of each individual was divided into two portions. The control sample was sham irradiated, whereas the other portion was irradiated with a dose of 2 Gy by a 6MV linear accelerator (Mevatron, Siemens, Germany). The lymphocytes were stimulated with phytohemagglutinin and cultivated in the incubator. Lymphocytes were grown for $48 \mathrm{~h}$ and were blocked in the metaphase by colcemid and chromosome preparations were performed. In order to detect chromosome 1, 2 and 4, the DNA was hybridized with chromosome specific probes. The staining was carried out by different fluorescent dyes and the whole DNA was counterstained with DAPI. The three color Fluorescence in situ hybridization (FiSH) was performed as previously described [14, 27, 28].

\section{Image acquisition and analysis}

A fluorescence microscope (Zeiss, Axioplan 2, Göttingen, Germany) and the Metasystems software (Metafer $4 \mathrm{~V} 3$. 10.1, Altlussheim, Germany) were used to search chromosome metaphase spreads automatically at $100 \times$ magnification and an image of each metaphase was acquired at a magnification of $630 \times$. For each metaphase spread black and white images of each color (red, green and blue) were acquired and used for evaluation (Additional file 1: Figure S1). With support of an image analysis software (Biomas, Erlangen, Germany) at least 100 
metaphases were analyzed and translocations, dicentric chromosomes, acentric chromosomes, rings, deletions, insertions and complex chromosomal rearrangements (CCRs) were scored and data transferred to a spreadsheet (Excel, Microsoft Corporation, Redmond, WA, USA) and scores $(\mathrm{B} / \mathrm{M})$ were calculated. The aberrations were scored by the number of underlying chromosomal breakages according to Savage and Simpson [21]. The B/M value of the irradiated sample was then corrected by the $B / M$ value of the sham irradiated sample.

\section{Statistical analysis}

The statistical analysis of the data was performed by SPSS Statistics 21 (IBM, Armonk, NY, USA) [29, 30]. Data were tested by the Levene-test and T-test, Pearson's $\mathrm{r}$ correlation, Spearman's rho correlation and Kolmogorov Smirnov test. Graphics were plotted using Excel (Microsoft Corporation, Redmond, WA, USA) or TechPlot 7 (SFTek, Braunschweig, Germany).

\section{Results}

\section{Cohort of healthy individuals and cancer patients}

In total, blood of 595 individuals of different ages was studied for radiosensitivity. The whole cohort consisted of 202 healthy individuals and 393 patients with various solid malignancies like rectal cancer, breast cancer, lung cancer, head and neck tumors, melanoma and prostate cancer (Table 1). The mean age of the healthy individuals was 50.7 years and the mean cancer patients' age was 60.4 years.

\section{Three-color fluorescence in situ hybridization}

Radiosensitivity was studied by a three color in situ hybridization assay. Peripheral blood was irradiated ex vivo by a dose of 2 Gy or left unirradiated. Lymphocytes were stimulated and arrested in the first cell division. Standard metaphases were prepared and the three-color FiSH assay was performed. Chromosomes 1, 2 and 4 of the metaphases were analyzed for chromosomal aberrations. Color changes along the three chromosomes were categorized as a chromosomal aberration and were scored according to as many break events were theoretically necessary for the constitution of the respective aberration. Acentric fragments, deletions and open breaks were scored as one break event; translocations, dicentrics and ring chromosomes were scored as two break events; insertions were scored as three breaks events and for complex chromosome aberrations the number of underlying break events was calculated (Fig. 1a-d) as proposed by Savage et al. [21]. The average aberration frequency is expressed as breaks per metaphase $(B / M)$. In previous studies we found that from a value of $0.5 \mathrm{~B} / \mathrm{M}$ on an increased radiosensitivity can be assumed and from a value of $0.6 \mathrm{~B} / \mathrm{M}$ on an individual is considered to have a distinctly increased radiosensitivity $[19,28]$.

\section{$B / M$ values and age in healthy individuals and cancer patients}

We studied the distribution of $\mathrm{B} / \mathrm{M}$ values in the healthy individuals and cancer patient cohort (Fig. 1f, g). A Gaussian fit for the healthy individuals was applied and the two times standard deviation was used as cut off. In the group of healthy individuals $10.4 \%$ and among cancer patients $25.7 \%$ were outliers, exceeding the two times standard deviation (Fig. 1f). Similarly, after 2 Gy ex vivo irradiation and correction by background levels we found more outliers in the patients' group (11.5\%) than in the group of healthy individuals $(5.9 \%$, Fig. $1 \mathrm{~g}$ ).

Furthermore, the age of healthy individuals and the 2Gy $\mathrm{B} / \mathrm{M}$ values (corrected) of each individual were tested for correlation. $2 \mathrm{~Gy} \mathrm{~B} / \mathrm{M}$ values increased clearly with age by $0.0014 \mathrm{~B} / \mathrm{M}$ per year $(r=0.246, p=0.01)$ in the healthy individual cohort. With a mean age of 50.7 years the healthy individual cohort had a mean $\mathrm{B} / \mathrm{M}$ value of $0.42 \pm 0.104$. Mean $\mathrm{B} / \mathrm{M}$ values raised from 0.39 at the age 30 to $0.44 \mathrm{~B} / \mathrm{M}$ at the age 75 (Fig. 2a). In the patient cohort no correlation of age and $\mathrm{B} / \mathrm{M}$ values was found $(p=0.343)$ and the slope of the line tended to be negative. The mean age of patients was 60.4 years with a mean $\mathrm{B} / \mathrm{M}$ value of $0.44 \pm 0.150$ (Fig. $2 b$ ).

We presumed that there is an age dependency of $B / M$ values and therefore divided the cohorts into different age groups. In average the cohort of healthy individuals was younger than the cancer patients' group. To have sufficient numbers of individuals in each group we divided the cohorts into age groups of at least 24 individuals (Fig. 2c, d). The mean age of the healthy individuals groups was 24, 32, 50, 61 and 75 years, respectively, and of the cancer patients the mean age was $32,48,59,71$ and 82 years, respectively. $\mathrm{B} / \mathrm{M}$ values were clearly increased when comparing the youngest healthy individuals group of 24 years to the older individuals of $50(p=$ 0.027), $61(p<0.001)$ and 75 years $(p=0.001)$ (Fig. 2c). In the patient cohort $\mathrm{B} / \mathrm{M}$ values do not differ between the age groups (Fig. 2d). In the cancer patient subgroups of rectal cancer patients $(n=203)$ (Fig. 2e) and breast cancer patients $(n=101)$ (Fig. 2f) was no change in radiosensitivity over age. Since more outliers were observed among cancer patients compared to the cohort of healthy individuals (Fig. 1f,g) we further focused on the outliers in the different age groups. Here, we used our previously defined threshold values for increased radiosensitivity $[19,28]$. In the healthy individuals cohort there was a clear increase of outliers with age in the group of individuals having $\mathrm{B} / \mathrm{M}$ values higher than 0.5 and individuals with $\mathrm{B} / \mathrm{M}$ values higher than $0.6(\rho=0.9$, $p=0.037$ ). Each year the percentage of individuals with 

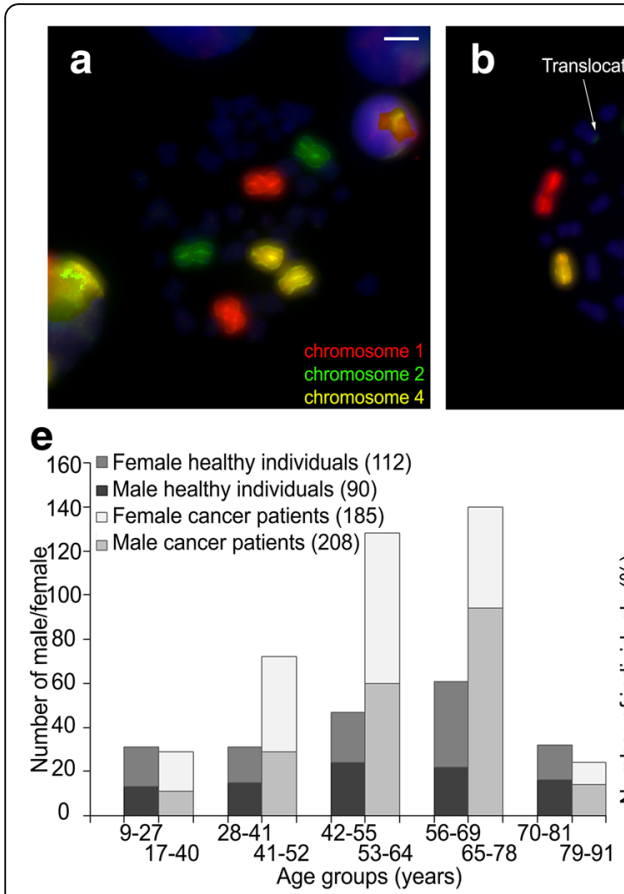

Fig. 1 Three-color fluorescence in situ hybridization to determine radiosensitivity. Metaphase spreads of human blood lymphocytes, stained with chromosome specific probes for chromosome \# 1 (red, rhodamine), chromosome \# 2 (green, FITC) and chromosome \# 4 (yellow, rhodamine + FITC). DNA was stained with DAPI (blue) (a-d). Normal metaphase spread (a). Metaphase spread with two translocations of \# 2 with a blue chromosome and \# 4 with a blue chromosome and an insertion of \# 1 into a blue chromosome. The three aberrations were scored as 7 breaks (b). Metaphase spread with a dicentric chromosome of \# 1 and \# 2, a translocation of \# 1 and \# 4 and an insertion of \# 1, \# 2 and \# 4. The aberrations were scored as 5 breaks (c). Metaphase spread with complex chromosomal rearrangements (CCR). The aberrations were scored as 12 breaks (d). Gender distribution of 202 healthy individuals in different age groups (9-27, 28-41, 42-55, 56-69 and 70-81 years) and of 393 patients with various cancer diseases (17-40, 41-52, 53-64, 65-78, 79-91 years) (e). Number of healthy individuals and cancer patients classified into divisions of 0.02 breaks per metaphase. Zero point five B/M (dashed line) and 0.6 B/M (solid line) are marked as a cutoff point to increased and distinctly increased radiosensitivity. B/M background without irradiation ( $\mathbf{f}$ ) and after irradiation of 2 Gy, corrected by the background ( $\mathbf{g}$ ). The data were fitted using a Gaussian distribution; scale $10 \mu \mathrm{m}$

a $\mathrm{B} / \mathrm{M}$ value higher than 0.6 , grows by $0.64 \%$ (Fig. $2 \mathrm{~g}$ ). In the cancer patient cohort there was a high proportion of individuals having values higher than $0.5 \mathrm{~B} / \mathrm{M}$, yet without an increase with age. However the proportion of cancer patients with values higher than $0.6 \mathrm{~B} / \mathrm{M}$ increased clearly with age, each year by $0.76 \%(\rho=0.9$, $p=0.037$ ) (Fig. 2g).

Next we were interested whether there is an age cut off for the $\mathrm{B} / \mathrm{M}$ values between healthy individuals and patients. We categorized subgroups comprising younger and equal or older individuals from 40 to 70 years at 10 year intervals. Among the young groups healthy individuals had distinctly lower $\mathrm{B} / \mathrm{M}$ values than cancer patients at age $40(p=0.007), 50(p<0.001), 60(p=0.001)$ and 70 $(p=0.013)$. But there was no difference between healthy individuals and patients of groups equal or older than 40, 50, 60 and 70 years (Fig. 3a). In the different age groups younger healthy individuals had lower $\mathrm{B} / \mathrm{M}$ values than older and exactly the opposite is the case in younger cancer patients having higher $\mathrm{B} / \mathrm{M}$ values than older. These differences decreased in the older age groups (Fig. 3a).

\section{Complex chromosomal aberrations and age}

It was previously published that complex chromosomal aberrations are especially suited to predict individual radiosensitivity [28]. So we studied CCR in both groups separately. In healthy individuals CCR per metaphase $(\mathrm{CCR} / \mathrm{M})$ clearly increased between the age group 24 and $50(p=0.003), 24$ and $61(p<0.001)$ and 24 and 75 years $(p=0.001)$ (Fig. 3b). Between age groups of cancer patients CCR/M there was no difference (Fig. 3c).

\section{Discussion}

We used the 3C-FiSH to analyze chromosomal aberrations after ex vivo irradiation. A healthy individual cohort and a cancer patient cohort were studied. In the cancer patient cohort a considerable portion of individuals with increased radiosensitivity was expected, because individuals with impaired DNA damage processing are more prone to cancer [31]. About 20\% of all cancers are assumed to have a genetic background [32] divided in inherited high penetrance genes and familial low penetrance genes with polygenetic mechanisms. In breast cancer up 

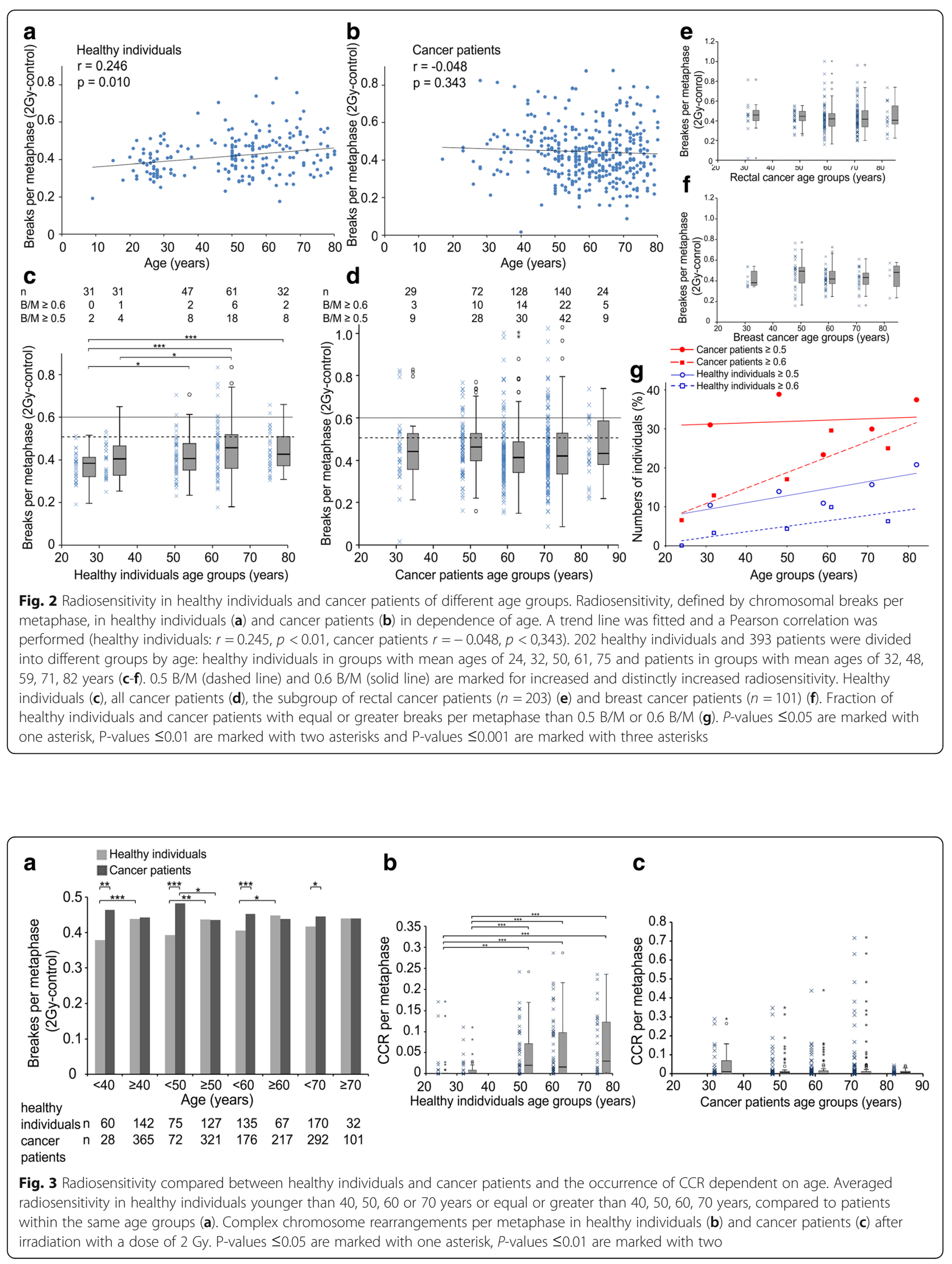
to $50 \%$ of cases might be related to a genetic cause [33]. Especially in young cancer patients due to their higher proportion of genetically caused cancers [34], a high amount of cancer patients with increased radiosensitivity was assumed. The consequence is that a relationship between age and radiosensitivity was not found.

So we used a second cohort of healthy individuals with no history of malignant disease. Here, a clear increase of the individual radiosensitivity with age was found. However, this mild overall increase will probably not increase radiotherapy related side effects. In the cancer patient cohort no such age dependent increase of radiosensitivity was found. The reason may be that at young age the proportion of genetically caused cancers is higher compared to older individuals. At older age there are probably still higher amounts of genetically induced cancers, however the portion of sporadic cancers without an increased radiosensitivity is higher than in the young age group.

More important for clinical radiotherapy and the occurrence of treatment related side effects may be the amount of outliers in the different age groups. We assume a distinctly increased radiosensitivity starting with a $\mathrm{B} / \mathrm{M}$ of 0.6 and recommend reducing the radiation dose in these patients $[26,35,36]$. None of the young healthy individuals had a $\mathrm{B} / \mathrm{M}$ value above 0.6 whereas $6.3 \%$ had increased $\mathrm{B} / \mathrm{M}$ values at age 75 . In the cancer patient cohort at age 31 already $10.3 \%$ of patients had B/ $M$ values above 0.6 and this portion rose to $20.8 \%$ at age 82. So the fraction of cancer patients with distinctly increased radiosensitivity clearly increased with age. There are only limited studies dealing with chromosomal radiosensitivity and age. A study comparing radiosensitivity of ten new borns using umbilical cord blood compared with twenty adults did not find an increase with age, but a distinct higher radiosensitivity of newborns [37]. Similar in a group of 14 individuals no influence of age on dicentric aberrations was found [38]. In a breast cancer cohort of 100 patients age at onset of disease did not correlate with radiosensitivity [39]. In a former study we found in a cohort of 67 breast cancer patients a high number of radiosensitive individuals between age 40 and 50 and afterwards a steep decline of radiosensitivity followed by a slow age dependent increase of radiosensitivity [26].

We used this 3-C FiSH approach because chromosomal aberrations in lymphocytes are particularly suited for the study of individual radiosensitivity. The advantage in analyzing aberrations is that all lymphocytes are irradiated in the G0 phase and therefore have no cell cycle dependent differences in radiosensitivity. After ex vivo irradiation lymphocytes have to process DNA damage and progress through the complete cell cycle up to mitosis. Additionally the lymphocytes may induce cell death. So all these lymphocytic abilities influence the chromosomal aberrations and therefore an impairment of these abilities will increase chromosomal aberrations and indicate increased radiosensitivity. Staining the chromosomes by fluorescent whole-chromosome (FISH) painting has the advantage that translocations and insertions are easily detected compared to conventional staining. We use a painting approach of chromosomes 1, 2 and 4 [35]. The three chromosomes are stained in red, green and yellow and are easily to distinguish and even small breaks or insertions of about $5 \mathrm{Mbp}$ can be identified [40]. Additionally the three chromosomes represent $23 \%$ of the genomic DNA [41] and are involved in about 34\% of all aberrations [42]. Painting all chromosomes by 24-C FiSH is challenging and the analyzing of the aberrations is even more complex [43]. Because by $3-\mathrm{C}$ FiSH only a fraction of all possible exchanges are detected, the number of metaphases examined is adjusted accordingly and results in equivalent frequencies of chromosome exchanges [42].

\section{Conclusions}

Individual radiosensitivity rises continuously with age, yet with strong interindividual variation. In cancer patients an age related increase of the individual radiosensitivity cannot be demonstrated due to the strong interindividual variation. However among old cancer patients there is a higher probability to have patients with clear increased radiosensitivity than in younger age.

\section{Additional file}

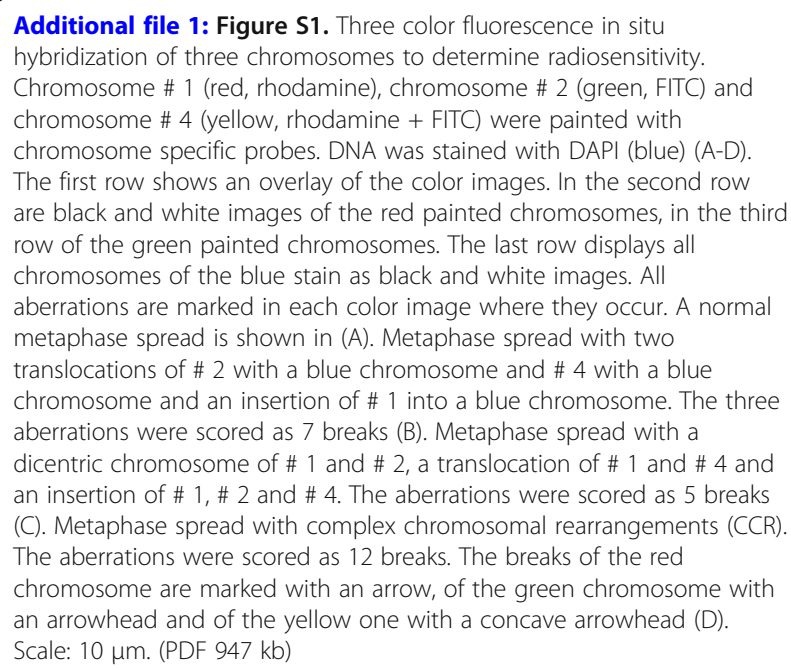

\section{Abbreviations}

3C-FiSH: 3 color-Fluorescence in situ hybridization; B/M: Breaks per metaphase; CCR: Complex chromosome rearrangement; CCR/M: Complex chromosome rearrangements per metaphase; DAPI: 4',6-Diamidin-2phenylindol; DNA: Deoxyribonucleic Acid; FiSH: Fluorescence in situ hybridization; FITC: Fluorescein isothiocyanate; Gy: Gray; h: hour;

ICD: International classification of diseases; n: Sample number 


\section{Acknowledgements}

The author would like to thank Doris Mehler and Elisabeth Müller for excellent technical support for the study and all individuals for donations of blood.

\section{Availability of data and materials}

The dataset used and analysed during the current study is available from the corresponding author on reasonable request.

\section{Authors' contributions}

BS generated the data, a part of the statistical analyses and drafted the manuscript. LD performed the statistical analysis and finalized the manuscript. A part of the data was generated by AE (rectal carcinoma patients), TM (lung carcinoma) and JA (breast cancer patients). RF designed and enabled this study. $\mathrm{MH} 1$ and $\mathrm{MH} 2$ were involved in the scientific analysis of the data, writing and reviewed the article with respect to language and understanding. All authors read and approved the final manuscript.

\section{Ethics approval and consent to participate}

This study was approved by the ethics review committee of the university Erlangen-Nürnberg (No. 2725). Written informed consent was obtained before enrollment from all patients and healthy volunteers.

\section{Competing interests}

$\mathrm{MH} 2$ reports a grant of Novartis and non-financial support and other from Merck Serono, outside the submitted work. The other authors declare no conflict of interest.

\section{Publisher's Note}

Springer Nature remains neutral with regard to jurisdictional claims in published maps and institutional affiliations.

\section{Author details}

'Department of Radiation Oncology, University Hospital Erlangen Friedrich-Alexander-Universität Erlangen-Nürnberg, Universitätsstr. 27, 91054 Erlangen, Germany. ${ }^{2}$ Department of Radiology, Charité Universitätsmedizin, Berlin, Germany.

Received: 31 January 2017 Accepted: 30 April 2018

Published online: 04 May 2018

\section{References}

1. Hernandez L, Terradas M, Camps J, Martin M, Tusell L, Genesca A. Aging and radiation: bad companions. Aging Cell. 2015;14(2):153-61.

2. Lilla C, Ambrosone CB, Kropp S, Helmbold I, Schmezer P, von Fournier D, Haase W, Sautter-Bihl ML, Wenz F, Chang-Claude J. Predictive factors for late normal tissue complications following radiotherapy for breast cancer. Breast Cancer Res Treat. 2007;106(1):143-50.

3. Sedelnikova OA, Horikawa I, Redon C, Nakamura A, Zimonjic DB, Popescu NC, Bonner WM. Delayed kinetics of DNA double-strand break processing in normal and pathological aging. Aging Cell. 2008; 7(1):89-100.

4. Endt H, Sprung CN, Keller U, Gaipl U, Fietkau R, Distel LV. Detailed analysis of DNA repair and senescence marker kinetics over the life span of a human fibroblast cell line. J Gerontol a-Biol. 2011;66(4):367-75.

5. Rube CE, Fricke A, Widmann TA, Furst T, Madry H, Pfreundschuh M, Rube C. Accumulation of DNA Damage in Hematopoietic Stem and Progenitor Cells during Human Aging. PLoS One. 2011:6(3)

6. Wenger B, Schwegler M, Brunner M, Daniel C, Schmidt M, Fietkau R, Distel LV. PML-nuclear bodies decrease with age and their stress response is impaired in aged individuals. BMC Geriatr. 2014;14:42.

7. Peuckmann V, Ekholm O, Rasmussen NK, Groenvold M, Christiansen P, Moller S, Eriksen J, Sjogren P. Chronic pain and other sequelae in long-term breast cancer survivors: nationwide survey in Denmark. Eur J Pain. 2009; 13(5):478-85.

8. Dehing-Oberije C, De Ruysscher D, van Baardwijk A, Yu S, Rao B, Lambin P. The importance of patient characteristics for the prediction of radiationinduced lung toxicity. Radiother Oncol. 2009;91(3):421-6.

9. Collette S, Collette L, Budiharto T, Horiot JC, Poortmans PM, Struikmans H, Van den Bogaert W, Fourquet A, Jager JJ, Hoogenraad W, et al. Predictors of the risk of fibrosis at 10 years after breast conserving therapy for early breast cancer: a study based on the EORTC trial 22881-10882 'boost versus no boost'. Eur J Cancer. 2008;44(17):2587-99.

10. Barnett GC, Wilkinson JS, Moody AM, Wilson CB, Twyman N, Wishart GC, Burnet NG, Coles CE. The Cambridge breast intensity-modulated radiotherapy trial: patient- and treatment-related factors that influence late toxicity. Clin Oncol. 2011;23(10):662-73.

11. Scott D. Chromosomal radiosensitivity, cancer predisposition and response to radiotherapy. Strahlenther Onkol. 2000;176(5):229-34.

12. Jones LA, Scott D, Cowan R, Roberts SA. Abnormal radiosensitivity of lymphocytes from breast cancer patients with excessive normal tissue damage after radiotherapy: chromosome aberrations after low dose-rate irradiation. Int J Radiat Biol. 1995:67

13. Dunst J, Neubauer S, Becker A, Gebhart E. Chromosomal in vitro radiosensitivity of lymphocytes in radiotherapy patients and AThomozygotes. Strahlenther Onkol. 1998;174

14. Neubauer S, Dunst J, Gebhart E. The impact of complex chromosomal rearrangements on the detection of radiosensitivity in cancer patients. Radiother Oncol. 1997:43(2):189-95.

15. Baeyens A, Thierens H, Claes K, Poppe B, Messiaen L, De Ridder L, Vral A. Chromosomal radiosensitivity in breast cancer patients with a known or putative genetic predisposition. Br J Cancer. 2002;87(12):1379-85.

16. Hoeller U, Borgmann K, Bonacker M, Kuhlmey A, Bajrovic A, Jung H, Alberti W, Dikomey E. Individual radiosensitivity measured with lymphocytes may be used to predict the risk of fibrosis after radiotherapy for breast cancer. Radiother Oncol. 2003;69

17. Huber R, Braselmann H, Geinitz H, Jaehnert I, Baumgartner A, Thamm R, Figel $M$, Molls $M$, Zitzelsberger $H$. Chromosomal radiosensitivity and acute radiation side effects after radiotherapy in tumour patients-a follow-up study. Radiat Oncol. 2011:6:32.

18. Scott D, Spreadborough AR, Jones LA, Roberts SA, Moore CJ. Chromosomal radiosensitivity in G2-phase lymphocytes as an indicator of cancer predisposition. Radiat Res. 1996;145(1):3-16.

19. Grabenbauer GG, Lahmer G, Distel L, Niedobitek G. Tumor-infiltrating cytotoxic T cells but not regulatory T cells predict outcome in anal squamous cell carcinoma. Clin Cancer Res. 2006:12(11 Pt 1):3355-60.

20. Tucker JD, Morgan WF, Awa AA, Bauchinger M, Blakey D, Cornforth MN, Littlefield LG, Natarajan AT, Shasserre C. A proposed system for scoring structural aberrations detected by chromosome painting. Cytogenet Cell Genet. 1995;68(3-4):211-21.

21. Savage JR, Simpson P. On the scoring of FISH-"painted" chromosome-type exchange aberrations. Mutat Res. 1994;307(1):345-53.

22. Barber JB, Burrill W, Spreadborough AR, Levine E, Warren C, Kiltie AE, Roberts SA, Scott D. Relationship between in vitro chromosomal radiosensitivity of peripheral blood lymphocytes and the expression of normal tissue damage following radiotherapy for breast cancer. Radiother Oncol. 2000:55(2):179-86.

23. Baria K, Warren C, Roberts SA, West CM, Scott D. Chromosomal radiosensitivity as a marker of predisposition to common cancers? $\mathrm{Br}$ J Cancer. 2001;84(7):892-6.

24. Beaton LA, Marro L, Samiee S, Malone S, Grimes S, Malone K, Wilkins RC Investigating chromosome damage using fluorescent in situ hybridization to identify biomarkers of radiosensitivity in prostate cancer patients. Int J Radiat Biol. 2013;89(12):1087-93.

25. Popanda O, Ebbeler R, Twardella D, Helmbold I, Gotzes F, Schmezer P Thielmann HW, von Fournier D, Haase W, Sautter-Bihl ML, et al. Radiationinduced DNA damage and repair in lymphocytes from breast cancer patients and their correlation with acute skin reactions to radiotherapy. Int J Radiat Oncol Biol Phys. 2003;55(5):1216-25.

26. Auer J, Keller U, Schmidt M, Ott O, Fietkau R, Distel LV. Individual radiosensitivity in a breast cancer collective is changed with the patients' age. Radiol Oncol. 2014;48(1):80-6.

27. Gebhart E, Neubauer S, Schmitt G, Birkenhake S, Dunst J. Use of a threecolor chromosome in situ suppression technique for the detection of past radiation exposure. Radiat Res. 1996;145(1):47-52.

28. Keller U, Kuechler A, Liehr T, Muller E, Grabenbauer G, Sauer R, Distel $\mathrm{L}$. Impact of various parameters in detecting chromosomal aberrations by FISH to describe Radiosensitivity. Strahlenther Onkol. 2004;180(5): 289-96.

29. Hasegawa T, Someya M, Hori M, Matsumoto Y, Nakata K, Nojima M, Kitagawa M, Tsuchiya T, Masumori N, Hasegawa T, et al. Expression of Ku70 
predicts results of radiotherapy in prostate cancer. Strahlenther Onkol. 2017; 193(1):29-37.

30. Oskan F, Becker G, Bleif M. Specific toxicity after stereotactic body radiation therapy to the central chest : a comprehensive review. Strahlenther Onkol. 2017;193(3):173-84.

31. Moses RE. DNA damage processing defects and disease. Annu Rev Genomics Hum Genet. 2001;2:41-68.

32. Nagy R, Sweet K, Eng C. Highly penetrant hereditary cancer syndromes. Oncogene. 2004;23(38):6445-70.

33. Houlston RS, Peto J. The search for low-penetrance cancer susceptibility alleles. Oncogene. 2004;23(38):6471-6.

34. Dite GS, Jenkins MA, Southey MC, Hocking JS, Giles GG, McCredie MR, Venter DJ, Hopper JL. Familial risks, early-onset breast cancer, and BRCA and BRCA2 germline mutations. J Natl Cancer Inst. 2003;95(6):448-57.

35. Distel LV, Keller U, Neubauer S: Three-color FISH for the detection of individual Radiosensitivity: springer; 2009.

36. Distel LV, Neubauer S, Keller U, Sprung CN, Sauer R, Grabenbauer GG. Individual differences in chromosomal aberrations after in vitro irradiation of cells from healthy individuals, cancer and cancer susceptibility syndrome patients. Radiother Oncol. 2006;81(3):257-63.

37. Bakhmutsky MV, Joiner MC, Jones TB, Tucker JD. Differences in cytogenetic sensitivity to ionizing radiation in newborns and adults. Radiat Res. 2014; 181(6):605-16.

38. Pajic J, Rakic B, Rovcanin B, Jovicic D, Novakovic I, Milovanovic A, Pajic V. Inter-individual variability in the response of human peripheral blood lymphocytes to ionizing radiation: comparison of the dicentric and micronucleus assays. Radiat Environ Biophys. 2015;54(3):317-25.

39. Baeyens A, Van Den Broecke R, Makar A, Thierens H, De Ridder L, Vral A. Chromosomal radiosensitivity in breast cancer patients: influence of age of onset of the disease. Oncol Rep. 2005;13(2):347-53.

40. Schilling S, Keller U, Sprung CN, Weise A, Grabenbauer GG, Sauer R, Distel L. Breakpoint locations within chromosomes 1, 2, and 4 of patients with increased radiosensitivity. Cancer Genet Cytogenet. 2006;168(1):1-10

41. Morton NE. Parameters of the human genome. Proc Natl Acad Sci U S A. 1991;88(17):7474-6.

42. Tucker JD, Ramsey MJ, Lee DA, Minkler JL. Validation of chromosome painting as a biodosimeter in human peripheral lymphocytes following acute exposure to ionizing radiation in vitro. Int J Radiat Biol. 1993; 64(1):27-37.

43. Kuechler A, Neubauer S, Grabenbauer GG, Claussen U, Liehr T, Sauer R, Wendt TG. Is 24-color FISH detection of in-vitro radiation-induced chromosomal aberrations suited to determine individual intrinsic radiosensitivity? Strahlenther Onkol. 2002;178(4):209-15.

\section{Ready to submit your research? Choose BMC and benefit from:}

- fast, convenient online submission

- thorough peer review by experienced researchers in your field

- rapid publication on acceptance

- support for research data, including large and complex data types

- gold Open Access which fosters wider collaboration and increased citations

- maximum visibility for your research: over $100 \mathrm{M}$ website views per year

At BMC, research is always in progress.

Learn more biomedcentral.com/submissions 